\title{
The need to review knowledge gaps on sudden cardiac death in Canadian Indigenous populations
}

\section{LETTER TO THE EDITOR}

Sir,

It is known that the prevalence and mortality of cardiovascular disease are disproportionately higher in Indigenous peoples of Canada (First Nations, Métis, and Inuit). ${ }^{1}$ Sudden cardiac death is responsible for approximately one-half of all deaths from cardiovascular disease globally. However, the incidence of sudden cardiac death has not been specifically described for Canadian Indigenous populations, ${ }^{2}$ and it is unclear what modifiable factors should be addressed to improve the prevention, recognition, and treatment. Therefore, there is need for a national strategy to address the knowledge gaps regarding sudden cardiac death in Indigenous peoples.

The disparities in determinants of cardiovascular health between Indigenous and non-Indigenous persons are well documented. An unequal burden of poverty, inequities in medical treatment, along with socioeconomic factors stemming from historic governmental policies that disrupted Indigenous societies, all contribute toward the increased prevalence of cardiovascular disease. ${ }^{1}$ Bresee and colleagues found that across urban and remote geographies, First Nations people were less likely to receive coronary angiography within 24 hours of myocardial infarction and more likely to die from sudden cardiac death. ${ }^{3}$ Remote Indigenous communities experience higher mortality rates from poorer emergency medical service (EMS) response time, a lack of permanent road access, and hazardous conditions. ${ }^{4}$ Early defibrillation remains the key to survival in arrhythmias leading to sudden cardiac death, hence acknowledging challenges of providing timely resuscitation is important. Furthermore, genetic differences between Indigenous and non-Indigenous populations should be considered. Arbour and colleagues found at least three different Canadian Indigenous communities have a disproportionately higher rate of congenital long QT syndrome. ${ }^{5}$ The culmination of these socioeconomic, epidemiological, and genetic risk factors place Indigenous populations at higher risk of sudden cardiac death and require a unique approach to optimize survival outcomes. ${ }^{5}$

We propose the development of a national strategy to address this. First, it will be important to gather input from key stakeholders including EMS, Indigenous leaders, medical/public health representatives, and various governmental healthcare experts. Second, developing an efficient method of tracking cardiac arrests will be necessary. Involving the Canadian Sudden Cardiac Arrest
Network Registry, which is working to build Canada's first database of sudden cardiac death cases, will be valuable. Lastly, Indigenous communities face barriers to many basic services, which have a significant impact on general health including cardiovascular disease. This project will serve as a window into one of many serious public health deficiencies that affect overall Indigenous health. It is hoped that by highlighting gaps in care with sudden cardiac death in Indigenous communities, attention to other public health needs will be addressed.

\section{Matthew Sem}

Faculty of Medicine, University of Toronto, Toronto, ON

Steve Lin, MD, MSc

Emergency Physician, Trauma

Team Leader, Department of Emergency Medicine, St. Michael's Hospital, Toronto, ON

Scientist, Li Ka Shing Knowledge Institute, St. Michael's Hospital, Toronto, ON

Assistant Professor, Faculty of Medicine, University of Toronto, Toronto, ON

Jeff Reading, MSc, PhD

British Columbia First Nations Health Authority Chair in Heart

Correspondence to: Matthew Sem, Faculty of Medicine, University of Toronto, 1 King's College Cir, Toronto, ON M5S 1A8; Email: matthew.sem @ mail.utoronto.ca

This article has been updated; see https://doi.org/10.1017/cem.2020.26.

(c) Canadian Association of Emergency Physicians 2020 


\section{Health \& Wellness, St. Paul's Hospital \\ Director, I-HEART Centre, Division of Cardiology, St. Paul's Hospital, Providence Health Care, Vancouver, BC \\ Professor, Faculty of Health Sciences, Simon Fraser University, Burnaby, BC}

Professor, Emeritus, Faculty of Health Sciences, University of Victoria, Victoria, BC

Adjunct Professor, Dalla Lana Faculty of Public Health, University of Toronto, Toronto, ON

Rohit Mohindra, MASc, MD

Emergency Physician and Research Scientist, Department of Emergency Medicine, North York General Hospital, Toronto, ON

Visiting Scientist, Li Ka Shing Knowledge Institute, St. Michael's Hospital, Toronto, ON

Keywords: Aboriginal health, cardiac arrest, quality improvement

Competing interests: The authors do not have any conflicts of interests to disclose.

\section{REFERENCES}

1. Smylie J, O'Brien K, Xavier CG, et al. Primary care intervention to address cardiovascular disease medication health literacy among Indigenous peoples: Canadian results of a prepost-design study. Can 7 Public Health 2018;109(1):117-27.
2. Wong CX, Brown A, Lau DH, et al. Epidemiology of sudden cardiac death: global and regional perspectives. Heart Lung Circ 2019;28:6-14.

3. Bresee LC, Knudtson ML, Zhang J, et al. Likelihood of coronary angiography among First Nations patients with acute myocardial infarction. CMA7 2014;186(10):E372-80.

4. Curran J, Ritchie SD, Beardy J, et al. Conceptualizing and managing medical emergencies where no formal paramedical system exists: perspectives from a remote Indigenous community in Canada. Int 7 Environ Res Public Health 2018;15(2): pii: E267.

5. Arbour L, Asuri S, Whittome B, Polanco F, Hegele RA. The genetics of cardiovascular disease in Canadian and international aboriginal populations. Can 7 Cardiol 2015;31(9):1094115 . 